УДК 94(=161.1):94(71)

DOI dx.doi.org/10.24866/1813-3274/2020-2/76-90

В. А. Хабибулин ${ }^{1}$, Дальневосточный федеральный университет,

г. Владивосток, Россия

E-mail: vak2411@mail.ru

Г. А. Казачун ${ }^{2}$, Дальневосточный федеральный университет,

г. Владивосток, Россия

E-mail: kazachun@mail.ru

\title{
ИНСТИТУЦИОНАЛИЗАЦИЯ РУССКОЯЗЫЧНЫХ ОБЩИН КАНАДЫ
}

Аннотащия. Страна кленового листа представлена этническими группами практически из всех стран мира. Свой вклад в её развитие внесли и выходцы из России. Крайняя разнородность русскоязычного населения, по разным причинам и в разных условиях переселявшегося в Канаду в течение полутора столетий, его неодинаковая идейно-политическая, религиозная ориентация, социально-классовая принадлежность, образовательный, профессиональный и культурный уровень детерминировали максимальную мозаичность и разобщённость общины, что препятствовало её превращению в активного и весомого участника канадской общественной, политической и культурной жизни. Бережное сохранение и продвижение многими этническими общностями Канады своей культуры, обычаев и традиций, поддержка государства и общества развития этого «многоцветья культур» предопределили изменения и в русскоязычных общинах. Создание по всей стране организаций, центров широкого спектра деятельности, в том числе поддержки соотечественников, сохранения и продвижения русской культуры, свидетельствуют о наметившейся тенденции к её консолидации и интеграции в канадское общество как русских канадцев.

\footnotetext{
${ }^{1}$ Владимир Асхатович Хабибулин, кандидат филологических наук, доцент кафедры международных отношений Восточного Института - Школы региональных и международных исследований Дальневосточного федерального университета, г. Владивосток, Россия.

${ }^{2}$ Галина Александровна Казачун, кандидат исторических наук, доцент, Дальневосточный федеральный университет, г. Владивосток, Россия.

Для иитирования: Хабибулин В. А., Казачун Г. А. Институционализация русскоязычных общин Канады // Азиатско-Тихоокеанский регион: экономика, политика и право. 2020. № 2. С. 76-90.
}

(C) Хабибулин В. А., Казачун Г. А., 2020 
Немаловажным фактором этого процесса становится поддержка Россией этнокультурной и духовной самоидентификации соотечественников как одно из ключевых направлений её внешней политики.

В статье рассматривается процесс институционализации русскоязычного сообщества в Канаде, его консолидации в последние десятилетия в условиях изменения состава иммигрантов, политики мультикультурализма как модели национальной интеграции, опирающейся на признание культурного многообразия этносов в качестве основы национального единства, эволюции отношения российского общества и государства к зарубежным соотечественникам.

Ключевые слова: иммиграция, русскоязычные общины, мультикультурализм, самоидентификация, консолидация, интеграция, адаптация, институционализация, зарубежные соотечественники, волны российской иммиграции, русский контент, национальное сообщество, культурное разнообразие этносов, центры русской культуры, «Русский мир», концепция внешней политики России.

Vladimir A. Khabibulin ${ }^{1}$, Far Eastern Federal University, Vladivostok, Russia E-mail: vak2411@mail.ru

Galina A. Kazachun², Far Eastern Federal University, Vladivostok, Russia E-mail: kazachun@mail.ru

\section{INSTITUTIONALIZATION OF RUSSIAN-SPEAKING COMMUNITIES OF CANADA}

Abstract. The article analyses the process of institutionalization of Russianspeaking communities in Canada and the consolidation of the population at the Canadian multiculturalism condition as the model of a national integration. Canada has accumulated a valuable experience of a peaceful way to solve many problems. One of the most essential factors here is its division into two state-forming communities: English and French Canadians. In Canada there are many different ethnic groups; Russian-speaking diaspora is one of many communities. Extreme diversity of the Russian-speaking population, who, due to various reasons and in different circumstances, had been immigrating in Canada for a century and a half, determined the highest mosaic structure and dissociation of the community that prevented it from becoming an active and weighty participant in the so-

\footnotetext{
${ }^{1}$ Vladimir A. Khabibulin, PhD (Philology), Associate professor, Department of International Studies, Oriental Institute - School of Regional and International Studies, Far Eastern Federal University, Vladivostok, Russia.

${ }^{2}$ Galina A. Kazachun, PhD (History), Associate professor, Far Eastern Federal University, Vladivostok, Russia. For citing: Khabibulin V. A., Kazachun G. A. Institutionalization of Russian-speaking communities of Canada // PACIFIC RIM: Economics, Politics, Law. 2020. No 2. P. 76-90.
} 
cial, political and cultural life of Canada. In the circumstance of careful preservation and promotion by many ethnic groups of their culture, customs and traditions together with a powerful public and social support of this cultural diversity (the image of the Maple Leaf country in the world) which are conducted in the context of multicultural policy, visible changes appeared in the Russian-speaking expat community as well. The intensive activity of Russian-speaking community in creating various associations and centers to support compatriots, to preserve and to promote Russian culture in the last decade, witnesses an outlined trend of rallying in the Russian community and its integration to the Canadian society as Russian Canadians.

Nowadays Russian Government regards the compatriots' problems as the key problems to Russian foreign policy and believes necessary to support Canadian compatriots according to their ethno-cultural and common self-identification.

Keywords: immigration, Russian-speaking communities, multiculturalism, selfidentification, consolidation, integration, adaptation, institutionalization, foreign compatriots, national association, cultural variety of ethnics, centers of Russian culture, conception of Russian foreign policy.

В последнее десятилетие актуализируются проблемы, связанные с русскоязычной диаспорой, её вкладом в развитие стран зарубежья, ролью русской культуры в мире. По своей численности (около 25-30 млн чел.) она занимает второе место после китайской. Самое большое число русскоязычного населения проживает в Казахстане - более 4 млн человек, в Германии - 3, 7 млн, в США - 3 млн [14]. В Канаде, по переписи 2016 г., численность русских несмешанного происхождения составила 120165 чел., «частично русскими» позиционировали себя 502280 чел. [28].

В солидной историографии русского зарубежья русскоязычные канадцы весьма скромно представлены в научном дискурсе. Кроме того, в научном сообществе и общественном мнении закрепилось положение о слабой их организованности, разобщённости и «недружности», что не совсем справедливо и в отношении предыдущих этапов их истории и, тем более, не соответствует современному периоду процесса институционализации русскоязычной общины в Канаде ${ }^{1}$.

Исследователи выделяют несколько волн российской иммиграции. Первая дореволюционная, начавшаяся в последние десятилетия XIX в., связана с переселением в Канаду 8 тыс. немецких колонистов-меннонитов и гуттеритов, 7726 духо-

\footnotetext{
${ }^{1}$ В научной литературе проблема институционализации рассматривается в различных аспектах. Доминирующей является позиция, согласно которой институционализация определяется как процесс создания и оформления организационных, правовых и других структур для удовлетворения общественных потребностей или как закрепление социальных норм, правил, статусов и ролей, приведение их в систему.
} 
Хабибулин В. А., Казачун Г. А. Институционализация русскоязычных общин Канады

боров, нескольких тысяч русских евреев. Заметный след в освоении Канады, развитии её земледельческой культуры оставили духоборы. Более половины из 30 тыс. их потомков сохраняют знание русского языка в качестве родного. Духоборы попрежнему представляют наиболее сплочённую группу канадцев русского происхождения. Их объединяет «Союз духовных общин Христа» (создан в 1938 г.), издающий с 1943 г. журнал «Искра». Однако община с тревогой признает, что у молодого поколения уже далеко не русский менталитет и русский язык постепенно вытесняется из обращения. Знают и используют русский язык потомки российских немцев-гуттеритов (22 тыс.) и меннонитов (более 200 тыс.), хотя они не учитываются переписью как «русские» [21; 24; 26].

В конце XIX - начале XX в. в Канаду направились новые группы русских переселенцев. Дореволюционные иммигранты, среди которых были рабочие, крестьяне, бежавшие политические ссыльные, революционеры, устраивались на железную дорогу, шахты, фермы. Большинству русских въезд разрешался не как переселенцам, а как временным рабочим, что мешало им селиться компактно и изначально позиционировало их как изгоев в канадском обществе. Значительная их часть принималась на тяжёлую и грязную работу [11].

В те времена единственной социальной структурой, помогавшей иммигрантам физически и духовно выжить в суровых условиях малоосвоенной страны, была православная церковь. Первый православный приход был открыт в 1897 г. на севере провинции Альберты, вблизи города Эдмонтона, в общине, названной Восток. Значительная роль в становлении православия в «Канадской Руси» принадлежит епископу Тихону, будущему патриарху Всероссийскому, который с 1898 г. возглавлял Православную Церковь в Америке. В августе 1901 г. он отправился в Канаду. Его миссионерские путешествия $(1901,1903,1904)$ способствовали возникновению многих приходов, строительству первых храмов [4].

Продолжал и укреплял становление православия в Канаде архиепископ Платон. Основной проблемой русских он считал их разобщённость: «... в тех местах, где нет прихода, нет священника, нет и этой необходимой солидарности, некому сорганизовать их в одну дружную семью, и потому... над ними издеваются, их мучат и безбожно эксплуатируют...» [4]. Первоочередной задачей владыка считал заполнение этого духовного вакуума и предполагал открыть в большинстве поселений, в которых жили славянские переселенцы, церкви и школы.

К 1916 г. в Канаде насчитывалось более 60 храмов, 20 священников, был открыт монастырь. Канадская церковь обрела своего епископа Александра, викария Американской епархии. Начал выходить журнал «Канадская Православная Русь». В Виннипеге было учреждено Канадское духовное правление.

В последующие годы русские православные церкви создаются во многих больших городах всех провинций. Церковь становится одним из первых институ- 
тов, способствующих консолидации переселенцев из России. При ней создавались библиотеки, школы с преподаванием русского языка. Она вела огромную благотворительную деятельность, оказывая помощь новым иммигрантам и исторической Родине в тяжёлые для неё годы Великой Отечественной войны [17].

Проявляли стремление к объединению и русскоязычные иммигранты, обустраивавшиеся в промышленных центрах. В 1910 г. в Торонто они открыли клуб, библиотеку, где обсуждали проблемы адаптации, трудоустройства, защиты своих интересов. В 1913 г. создан «Русский прогрессивный клуб». В Монреале в 1910 г. 25 русских социалистов организовали дискуссионный кружок. В 1919 г. часть его членов, «максималисты» (около 400 человек), организовали «Общество технической помощи России». Были открыты курсы подготовки трактористов, водителей, механиков для тех, кто хотел вернуться на родину; организован сбор средств голодающему Поволжью. В 1921 г. Общество отправило в Россию две группы специалистов для создания хозяйств, предоставив им 50 тыс. долл. и технику [25; 26].

Вторая волна русской иммиграции - послереволюционная. В Канаде она не была столь значительной, отличалась низкой долей представителей интеллигенции и дворянства, которые предпочитали Западную Европу и США. Преобладали трудовые иммигранты с низким уровнем квалификации, в основном из западнобелорусских и западно-украинских регионов. Несмотря на бедность, необразованность, незнание языка, иммигранты второй волны оказались весьма деятельными. 05 марта 1930 г. в Торонто был учреждён «Русский рабочий клуб им. М. Горького» (РРК), с 1933 г. - «Русский рабоче-фермерский клуб им. М. Горького» (РРФК). Клубы создавали русские школы, оказывали помощь забастовочному движению. После нападения Германии на Советский Союз уже 23 июня 1941 г. их активисты приняли решение об организации комитетов помощи СССР - Родине, как они с уважением подчёркивали. Первые комитеты были созданы 17 июля в Монреале и 7 августа в Торонто. На первом всеканадском русском съезде, проходившем 3031 мая 1942 г. в Торонто, была основана «Федерация русских канадцев» (ФРК) «общественная культурно-просветительская организация, не примыкающая ни к какой политической партии». ФРК собирала средства для оказания помощи СССР, проводила митинги, концерты, благотворительные базары, в которых участвовали представители многих национальностей [16].

Третья волна иммиграции состояла преимущественно из «перемещённых» лиц, потерявших родину в годы Второй мировой войны. В их составе были коллаборационисты, пленные, угнанные в Германию, боявшиеся вернуться в Советский Союз. Многие из них скрывали своё происхождение, старались скорее «раствориться» в англо-канадском обществе. Они отличались «особой недружностью и отчуждённостью», чему не в малой степени способствовал рост русофобии, недоверия и подозрительности к ним в условиях «холодной войны» [21]. Части русско- 
Хабибулин В. А., Казачун Г. А. Институционализация русскоязычных общин Канады

язычного населения этой волны были присущи антисоветские настроения, что отражалось в создаваемых ими организациях и периодических изданиях.

В то же время продолжался процесс институционализации российских канадцев, стремившихся к сохранению и продвижению русской культуры. Попрежнему действовала Федерация русских канадцев. Данные о её численности к концу 1940-х противоречивы: от 2200 до 22700 членов [16; 21]. В 1950-е гг. функционировали 46 отделений ФРК. В открытых ими «Русских народных домах» показывали советские фильмы, проводились лекции о международном положении. Создавались библиотеки русской литературы, осуществлялись совместные проекты, обмен делегациями, отправка на учёбу в СССР молодёжи. Но к концу 1960-х гг. ФРК практически прекратила существование [16].

В 1950 г. было основано Русско-канадское культурно-просветительное общество (РККПО) в Торонто. Общество учредило «Русско-канадский благотворительный фонд культурного наследия» (РКФКН) им. М. Н. Благовещенской. Фонд осуществляет творческую, финансовую и организационную поддержку в области культуры, искусства, науки и образования в Канаде. Финансирование благотворительного фонда поддерживают приходы православной церкви, волонтёры. Содействие ему оказывают Посольство Российской Федерации в Канаде и Генеральное консульство в Торонто [9].

С 2007 г. РККПО и РКФКН им. М. Н. Благовещенской под патронажем СвятоТроицкой Русской православной церкви за границей (Торонто), при сотрудничестве и содействии Русской торговой палаты (Russian Chamber of Commerce in Toronto) начали издавать русско-английский культурно-просветительский журнал «Наследие». На его страницах отражались разные аспекты духовной, культурной и общественной жизни. По словам главного редактора журнала М. Н. Благовещенской, их цель - пробуждать у людей интерес к величайшим достижениям русской культуры [1].

РККПО отмечает многие знаменательные даты русской истории, великих её людей. В 2014 г. Общество присоединилось к празднованию Всемирного дня русского единения, учреждённого в 2009 г. на II Международном форуме «СанктПетербург и молодые соотечественники: мосты сотрудничества в XXI веке». В мае 2016 г. РККПО открыло «Русский Дом», что способствовало расширению направлений и форм его работы.

«Русско-канадское культурно-просветительное общество» долгое время оставалось чуть ли не единственной общественной организацией, выступающей от лица русскоязычной иммиграции перед государственными и общественными структурами Канады. Оно внесло существенный вклад в сохранение и продвижение русской культуры, самоопределение русских, «постепенно, капелька за капелькой, осуществляя объединение и укрепление русской колонии», расширение связей с исторической Родиной [9]. 
Наиболее многочисленная группа канадцев российского происхождения представлена иммигрантами, приехавшими в 1980-1990-е гг., как правило, по израильской визе, в большинстве своём - русские еврейского происхождения. В соответствии с иммиграционным законодательством, установившим новые требования к желающим переселиться в Страну кленового листа (высокий профессионализм, экономическая активность, наличие достаточных средств и возможностей для открытия бизнеса, знание языка), изменился состав иммигрантов из России. Преобладали люди с высоким уровнем образования, востребованные на рынке профессионального труда. Части из них удалось открыть бизнес, сделать успешную карьеру [21].

Русскоязычная иммиграция последних двух десятилетий (пятая волна) сильно помолодела (средний возраст - около 33-х лет, но всё больше 23-летних выпускников вузов и 27-28-летних кандидатов наук). Её представители прагматичны, инициативны, напористы, много работают, хорошо владеют английским языком, компьютерными технологиями [22]. Они лишены политической предвзятости, у них нет чувства утраты и изгнания. Многие из них сохраняют российское гражданство, экономические, культурные связи с исторической родиной, им дороги русский язык, культура и традиции.

Практически по всей Канаде, как группой лиц, так и даже отдельными гражданами, создаются русские образовательные, культурные, общественные центры; организации, предлагающие широкий спектр информационных и профессиональных услуг, которым всё чаще отдают предпочтение соотечественники. Начался процесс объединения русскоязычных предпринимателей (Русская Торговая Палата в Торонто). Крупным событием в жизни русскоязычной общины стало открытие 19 декабря 2003 г. при поддержке канадского правительства и благотворительного фонда «Друзья Эрмитажа», занимающегося популяризацией русской культуры и музейного дела в Канаде, «Русской библиотеки» в Торонто [8].

Русская община Калгари (Канадское общество наций бывшего Советского Союза), созданная в 2004 г., основой консолидации соотечественников, их интеграции в местное сообщество считает предпринимательство. Её представители открывают магазины, парикмахерские, ремонтные мастерские, рестораны, школы и детские сады, спортивные секции, юридические и медицинские центры и т.д. [22].

Консолидируются русскоязычные иммигранты из бывших республик СССР. В 2008 г. создана «Канадская ассоциация русскоговорящих корейцев в Торонто» [20].

Стремительно нарастает русский контент в канадском информационном пространстве. Появляются новые газеты, журналы, теле- и радиопрограммы. Создан Интернет-центр русскоязычной общины Канады, на сайте которого представлены десятки общин и серверов. Информационные ресурсы ориентируются на широкий спектр интересов русскоязычного населения, различные этнические, социальные и конфессиональные, профессиональные группы, предлагают полезную информа- 
Хабибулин В. А., Казачун Г. А. Институционализация русскоязычных общин Канады

цию, практические советы по выбору места жительства, работе, учёбе, жилью, медицинскому обслуживанию и т.д. [6]. В социальной сети Facebook cоздана группа общественного движения «ДРУЗЬЯ - Russian Friends Group». Она призывает единомышленников оказывать реальную конкретную помощь людям, находящимся в трудных жизненных ситуациях (Давайте поможем себе сами!) [3].

Консолидации русскоязычных канадцев способствует деятельность, направленная на сохранение и продвижение русского языка и культуры. Формируются центры русской культуры. Среди них - Русский культурно-образовательный центр провинции Манитоба, Ассоциация русских актёров Монреаля, Канадский фонд русской культуры, Канадская ассоциация поддержки русскоязычной литературы и др.

В крупных городах страны созданы школы и образовательные центры по изучению русского языка и литературы. Широко известны: культурнообразовательный центр «Родник», культурно-образовательный центр и русская школа «Мечта», школа «Грамота» и др. Начали открываться русские детские садики (например, «Крошки-ножки» в Монреале).

Возникла необходимость в координации преподавания и изучения русского языка. 03 ноября 2012 г. по инициативе культурно-образовательного центра «Мечта», при поддержке Посольства РФ, Генерального консульства РФ в Монреале и «Координационного Совета Российских соотечественников Канады» (КСРСК) была созвана «Первая Всеканадская педагогическая конференции учителей и директоров дополнительных русскоязычных школ».

22 марта 2015 г. в Торонто состоялась первая практическая конференция «Я говорю по-русски» для учителей и родителей русскоговорящих детей-билингвов. Проведение конференции вызвало широкий отклик в русскоязычном сообществе: финансовую и информационную поддержку оказали около 40 организаций (ассоциации бизнесменов, торговые дома, благотворительные фонды, медиа-центры). В августе 2015 г. прошло Первое родительское собрание, которое называлось «Технологии эффективного обучения». В 2016 г. стартовал новый интернет-проект - еженедельный вебинар «Родительское собрание: доживём до понедельника» [10].

18 июля 2013 г. вышел первый в Канаде русскоязычный литературнохудожественный журнал «Новый свет», свидетельствующий о том, что в Канаде появились прозаики, поэты, публицисты, ярко и талантливо пишущие на русском языке [5].

Одним из факторов изменений в русскоязычном сообществе Канады является политика мультикультурализма (одна нация, два официальных языка, много этнических культур, т.е. единство - через многообразие), закреплённая в 1988 г. соответствующим актом [23]. Официально был провозглашён плюралистический подход к интерпретации сущности национального сообщества, получивший название мультикультурализма как модели национальной интеграции. Условием единства 
политической нации, понимаемой как единство граждан, признаётся культурное разнообразие её этносов. Государство и общество оказывают поддержку развитию этого культурного разнообразия, сохранению и продвижению этническими общностями своей культуры, обычаев и традиций, позиционируя «многоцветье культур» как особый имидж, визитную карточку Страны кленового листа в мировом сообществе. Многие из 165 этнических групп, представленных в Канаде, бережно сохраняют и продвигают свою культуру, обычаи, традиции, что не могло не повлиять на отношение русскоязычных иммигрантов к богатейшему культурному наследию страны их предков.

Одним из факторов консолидации русскоязычных канадцев является изменение политики России в отношении соотечественников. На протяжении всей драматической истории российской эмиграции государство и общество проявляли, мягко говоря, негативную реакцию к её представителям. Осознание проблем, связанных с соотечественниками, как ключевых для российской внешней политики проходило чрезвычайно болезненно. Концепция и государственная политика по поддержке соотечественников и соответствующая нормативно-правовая база разрабатываются с 1990-х гг. В 1994 г. образована Правительственная комиссия по делам соотечественников за рубежом (ПКДСР) [18]. В 1999 г. принят ФЗ «О государственной политике РФ в отношении соотечественников за рубежом», с изменениями и дополнениями от 23 июля 2010 г.[19]. В последнее десятилетие учреждены Фонд «Русский мир», Россотрудничество,Фонд поддержки и защиты прав соотечественников, проживающих за рубежом, создан портал «Русский век».

Концепция внешней политики РФ, принятая 30 ноября 2016 г., подтверждает базовые основы политики в отношении соотечественников: защита их прав и интересов; содействие консолидации, сохранению самобытности российской диаспоры и её связей с исторической Родиной, изучению и распространению русского языка, культуры; развитие системы российских культурных и образовательных организаций за рубежом [12].

Институтами, обеспечивающими взаимодействие соотечественников с общественными и государственными структурами РФ, являются Всемирный конгресс соотечественников (ВКС), его исполнительный орган - Всемирный координационный совет соотечественников, проживающих за рубежом; Всемирные конференции. Система Координационных советов создана во многих странах мира [2].

Координационный совет российских соотечественников Канады (КСРСК) оформлен на VII конференции соотечественников в Монреале 29 января 2009 г. Высшим его органом является ежегодная Страновая конференция. В планах КСРСК - открытие при поддержке МИД РФ и Россотрудничества Российского центра науки и культуры (в 2016 г. в 61 стране мира действовало 70 Российских центров науки и культуры), проведение годов, дней русской культуры и фестива- 
Хабибулин В. А., Казачун Г. А. Институционализация русскоязычных общин Канады

лей; издание при финансовой поддержке Посольства РФ всеканадской русской газеты; содействие культурному обмену; участие соотечественников в процессе модернизации России, укреплении её научного и технологического потенциала; создание комитета КСРСК по привлечению российского бизнеса и инвестиций в Канаду и канадского бизнеса и инвестиций в Россию; подготовка коллективных обращений в органы власти Канады и т.д. [4]. В 2014 г. председатель КСРСК Е. Клинаева избрана членом Всемирного координационного совета российских соотечественников за рубежом от Координационных советов Канады и США [2].

Одним из приоритетных направлений организаций русскоязычных общин становится работа с молодёжью. 27 ноября 2016 г. состоялась III Молодежная конференция Координационного совета организаций российских соотечественников Канады. Резолюция наметила ближайший план действий: создание единого интернет-портала новостей и событий, охватывающего все канадские регионы; налаживание полноценного диалога между русскоязычными общественными организациями и их диалога с правительственными учреждениями по актуальным проблемам и т.д. [13].

Таким образом, крайняя разнородность русскоязычного населения, в течение полутора столетий по разным причинам и в разных условиях переселявшегося в Канаду, его неодинаковая идейно-политическая, религиозная ориентация, социально-классовая принадлежность, образовательный, профессиональный и культурный уровень, опора на различные источники поддержки предопределяли мозаичность и разобщённость русскоязычного сообщества, препятствовали его превращению в активного и весомого участника канадской общественной, политической и культурной жизни. Процесс институционализации русских канадцев, продолжавшийся на протяжении всего ХХ столетия, значительно активизировался в последние два десятилетия. Важнейшей его составляющей является формирование организаций соотечественников, обеспечивающих адаптацию российских иммигрантов, защиту их политических, социально-экономических и этнокультурных интересов. Основными факторами консолидации русскоязычной диаспоры Канады являются изменения состава иммигрантов, канадская политика мультикультурализма, многосторонняя работа государственных и общественных институтов России по налаживанию контактов с зарубежными россиянами, поддержке и сохранению их самобытности, развитию и распространению русской культуры и языка.

Однако процесс институционализации и консолидации ещё далеко не завершён. Ранее созданные и вновь формируемые организации канадских россиян (Совет российских соотечественников Канады, Совет российских соотечественников в Канаде, Совет русскоязычных соотечественников Канады, Русский Конгресс Канады [15] и др.) пока не откликаются на призывы КСРСК к единству, наблюдается их острая конкуренция, борьба за лидерство в представлении интересов общины в Канаде и России. 
Среди многочисленных русскоязычных организаций зреет осознание необходимости консолидации общин, создания единой всеканадской организации соотечественников с целью успешной, в условиях канадского мультикультурализма и при участии исторической Родины, интеграции в поликультурное канадское сообщество как русских канадцев.

\section{Список литературы}

1. Благовещенская, М. Н. К 60-летию Русского культурно-просветительного общества. - URL: https://www.rcchf.ca/frontpage/60-years-togetherrussian.html (дата обращения: 24.04.2016).

2. Всемирный координационный совет российских соотечественников, проживающих за рубежом. - URL: http://vksrs.com (дата обращения: 18.10.2016).

3. ДРУЗЬЯ - Russian Friends Group (Canada). - URL: https://www.faceboo k.com/groups/RussianFriendsGroup (дата обращения: 02.11.2016).

4. Ефимов А. Б., Ласаева О. В. Становление православия в Канаде на рубеже XIX-XX вв. / А. Б. Ефимов, О. В. Ласаев // Вестник ПСТГУ. ІІ: История. История Русской Православной Церкви. - 2011. - Вып. 4 (41). - С. 60-75.

5. Жукова, А. Слово главного редактора. - URL: http://litsvet.com/in dex.php/8-litsvet/33-слово-главного-редактора (дата обращения: 20.12.2016).

6. Интернет-центр русскоязычной общины Канады. - URL: http://www.ca nadarussia.com/ (дата обращения: 25.04.2016).

7. Итоговая резолюция VI конференции российских соотечественников, проживающих в Канаде (Торонто, 6-7 ноября 2013 г). - URL: http://www.mi d.ru/mezdunarodnye-tematiceskie-konferencii/-/asset_publisher/tyy858jz7S6v/content/id /86398 (дата обращения: 19.04.2016).

8. Казачун, Г. А. Русские канадцы: на пути интеграции и самоидентификации / Г. А. Казачун, В. А. Хабибулин // Владивосток - точка возвращения: прошлое и настоящее русской эмиграции : материалы междунар. науч. конф., Владивосток, 68 октября 2014 г. - Владивосток : Изд-во Дальневост. ун-та, 2015. - С. 69-77.

9. Казачун, Г. А. Русско-канадское культурно-просветительное общество / Г. А. Казачун, В. А. Хабибулин // Владивосток - точка возвращения: прошлое и настоящее русской эмиграции : материалы Второй междунар. науч. конф. Владивосток, 12-14 октября 2016 г. - Хабаровск : РИО ДВЮИ МВД России, 2017. - С. 24 28.

10. Казачун, Г. А. Русское слово в Канаде: консолидация русскоязычной общины / Г. А. Казачун, В. А. Хабибулин // Культура и цивилизация. - 2017. - Т. 7, № 1A. - C. 49-59.

11. Комкова, Е. Г. Канадцы славянского происхождения в исторической перспективе // Этнокультурная мозаика Канады и проблемы канадской идентично- 
сти : материалы междисциплинарного семинара / отв. ред. В. А. Коленеко, В. И. Соколов. - Москва, 2003. - С. 41-51.

12. Концепция внешней политики Российской Федерации. 30 ноября 2016 г. - URL: https://www.mid.ru/web/guest/foreign_policy/official_documents//asse t_publisher/CptICkB6BZ29/content/id/2542248 (дата обращения: 09.12.2016).

13. Резолюция III Молодежной конференции Координационного совета организаций российских соотечественников Канады. - URL: https:/drive.google.co m/file/d/0B6WJZNDWbIfXY1VIRIhPS2RHcGc/view (дата обращения: 22.12.2016).

14. Русские общины в разных странах мира. - URL: http://russianworld.info/russkie-obschiny/ (дата обращения: 22.06.2017).

15. Русский Конгресс Канады: создать единое целое. - URL: http://russiancongresscanada.org/news-ru/1169/ (дата обращения: 09.12.16).

16. Семёнова, Л. Н. Белорусские корни русской трудовой иммиграции в Канаде в первой половине ХХ в. // Ойкумена. - 2011. - № 1. - С. 52-59.

17. Сергеев, О. И. Русская православная церковь в Северной Америке в первой половине XX в. // «Русская Америка»: материалы III Междунар. науч. конф. (Иркутск, 8-12 августа 2007 г.). - URL: http:/www.pribaikal.ru/iazitem/article/6193.html (дата обращения: 14.08.17).

18. Об основных направлениях государственной политики Российской Федерации в отношении соотечественников, проживающих за рубежом : указ Президента Российской Федерации от 11 августа 1994 № 1681. - URL: http:/www.kremlin.ru/acts/bank/6801 (дата обращения: 20.05.2016).

19. О государственной политике Российской Федерации в отношении соотечественников за рубежом : Федеральный Закон от 24 мая 1999 г. № 99-Ф3. URL: http://www.consultant.ru/document/cons_doc_LAW_23178/ (дата обращения: 08.06.2016).

20. Чен, В. Российские корейцы // Русская Канада. - 2008. - Март, № 101. URL: http://www.arirang.ru/news/2008/08027.htm (дата обращения: 09.10.2016).

21. Черкасов, А. И. Этнокультурная мозаика и межэтнические отношения в Канаде. Русские канадцы. - URL: http://www.niworld.ru/Statei/cherkasov/n1.htm (дата обращения: 14.02.2016).

22. Calgary Russian Community. - URL: http://zarubegom.com/russkayaobshhina-kalgari/ (дата обращения: 07.04.2016).

23. Canadian Multiculturalism Act. - URL: http://www.laws.justice.gc.ca/en/c18.7/30207.html (дата обращения: 04.03.2015).

24. Sergej Tolstoys and the Doukhobors: A Journey to Canada (Diary and correspondence) / ed. by A. Donskov. - Ottawa : University of Ottawa, 1998. - 402 p.

25. Multicultural Canada // Encyclopedia of Canada's Peoples. - URL: http://www.multiculturalcanada.ca/Encyclopedia/A-Z/i5/1 (дата обращения: 05.09.2013). 
26. Pierce, R. A. Russian Canadians. - URL: http://www.thecanadianencyclopedi a.ca/en/article/russian-canadians/ (дата обращения: 20.11.2016).

27. Russian-Canadian Cultural Aid Society. - URL: https://www.rcchf.ca/ (дата обращения:14.03.2016).

28. Statistics Canada. Data tables. 2016 Census. Ethnic Origin (279) - URL: http://www12.Statcan.gc/census-resensement/2016/dp-pd/dt-td/ (дата обращения: 20.02.2020).

\section{References}

1. Blagoveshchenskaya M.N. K 60-letiyu Russkogo kul'turno-prosvetitel'nogo obshchestva [To the 60th anniversary of the Russian cultural and educational society]. Available at: https://www.rcchf.ca/frontpage/60-years-together-russian.html (accessed 24 April 2016).

2. World Coordination Council of Russian Compatriots Living Abroad. Available at: http://vksrs.com (accessed 18 October 2016). (In Russian).

3. DRUZ"Ya - Russian Friends Group (Canada). - Available at: https://www.facebook.com/groups/RussianFriendsGroup (accessed 02 November 2016).

4. Efimov A. B., Lasaeva O. V. Stanovlenie pravoslaviya v Kanade na rubezhe XIX-XX vv. Vestnik PSTGU. II: Istoriya. Istoriya Russkoi Pravoslavnoi Tserkvi [Bulletin of the Orthodox St. Tikhon Monastery. II: History. History of the Russian Orthodox Church], 2011, iss. 4 (41),pp. 60-75.

5. Zhukova A. Slovo glavnogo redaktora [Word of the editor-in-chief]. Available at: http://itsvet.com/index.php/8-litsvet/33-slovo-glavnogo-redaktora (accessed 20 December 2016).

6. Internet Center of the Russian-speaking community of Canada. Available at: http://www.sanadarussia.com/ (accessed 25 April 2016). (In Russian).

7. Final resolution of the VI Conference of Russian Compatriots Living in Canada (Toronto, November 6-7, 2013). Available at: http://www.mid.ru/mezdunarodnyetematiceskie-konferencii/-/asset_publisher/tyy858jz7S6v/content/id/86398 (accessed 19 April 2016). (In Russian).

8. Kazachun G. A., Khabibulin V. A. Russkie kanadtsy: na puti integratsii i samoidentifikatsii [Russian Canadians: on the path of integration and self-identification]. Vladivostok - tochka vozvrashcheniya: proshloe i nastoyashchee russkoi emigratsii: materialy mezhdunar. nauch. konf., Vladivostok, 6-8 oktyabrya $2014 \mathrm{~g}$. [Vladivostok - the point of return: the past and the present of the Russian emigration: materials of the international. scientific. conf., Vladivostok, October 6-8, 2014]. Vladivostok: Far Eastern University Publ. House, 2015, pp. 69-77.

9. Kazachun G. A., Khabibulin V. A. Russko-kanadskoe kul'turno-prosvetitel'noe obshchestvo [Russian-Canadian cultural and educational society]. Vladivostok - 
tochka vozvrashcheniya: proshloe i nastoyashchee russkoi emigratsii: materialy Vtoroi mezhdunar. nauch. konf., Vladivostok, 12-14 oktyabrya 2016 g. [Vladivostok - the point of return: the past and the present of the Russian emigration: materials of the Second Intern. scientific. conf., Vladivostok, October 12-14, 2016]. Khabarovsk: Far Eastern Law Institute, Ministry of Internal Affairs of Russia Publ. House, 2017, pp. 24-28.

10. Kazachun G. A., Khabibulin V. A. Russkoe slovo v Kanade: konsolidatsiya russkoyazychnoi obshchiny [Russian word in Canada: consolidation of the Russianspeaking community]. Kul'tura i tsivilizatsiya, 2017, vol. 7, no. 1A, pp. 49-59.

11. Komkova E. G. Kanadtsy slavyanskogo proiskhozhdeniya $\mathrm{v}$ istoricheskoi perspektive [Canadians of Slavic origin in a historical perspective]. In: V. A. Koleneko, V. I. Sokolov (eds.) Etnokul'turnaya mozaika Kanady i problemy kanadskoi identichnosti: materialy mezhdistsiplinarnogo seminara [Ethnocultural mosaic of Canada and the problems of Canadian identity: materials of an interdisciplinary seminar]. Moscow, 2003, pp. 41-51.

12. The concept of foreign policy of the Russian Federation. November 30, 2016. Available at: https://www.mid.ru/web/guest/foreign_policy/official_documents//asset_p ublisher/CptICkB6BZ29/content/id/2542248 (accessed 09 December 2016). (In Russian).

13. Resolution of the III Youth Conference of the Coordination Council of organizations of Russian compatriots in Canada. Available at: https://drive.google.com/file/d /0B6WJZNDWbIfXY1VIRlhPS2RHcGc/view (accessed 22 December 2016). (In Russian).

14. Russian communities around the world. Available at: http://russianworld.info/russkie-obschiny/ (accessed 22 June 2017). (In Russian).

15. Russian Congress of Canada: create a unified whole. Available at: http://russiancongresscanada.org/news-ru/1169/ (accessed 09 December 16). (In Russian).

16. Semenova L. N. Belorusskie korni russkoi trudovoi immigratsii v Kanade $v$ pervoi polovine XX v. [Belarusian roots of Russian labor immigration in Canada in the first half of the twentieth century]. Oikumena, 2011, no.1, pp. 52-59.

17. Sergeev O. I. Russkaya pravoslavnaya tserkov' v Severnoi Amerike v pervoi polovine XX v. [The Russian Orthodox Church in North America in the first half of the twentieth century]. "Russkaya Amerika»: materialy III Mezhdunar. nauch. konf. (Irkutsk, 8-12 avgusta 2007 g.) [«Russian America»: materials of the III Intern. scientific. conf. (Irkutsk, August 8-12, 2007).]. Available at: http://www.pribaikal.ru/iaz-item/article/619 3.html (accessed 14 August 2017).

18. On the main directions of the state policy of the Russian Federation in relation to compatriots living abroad: Decree of the President of the Russian Federation of August 11, 1994 No. 1681. Available at: http://www.kremlin.ru/acts/bank/6801 (accessed 20 May 2016). (In Russian).

19. On the state policy of the Russian Federation in relation to compatriots abroad: Federal Law of May 24, 1999 No. 99-FZ. Available at: http://www.cons ultant.ru/document/cons_doc_LAW_23178/(accessed 08 June 2016). (In Russian). 
20. Chen V. Rossiiskie koreitsy [Russian Koreans]. Russkaya Kanada. 2008. Mart, no. 101. Available at: http://www.arirang.ru/news/2008/08027.htm (accessed 09 October 2016).

21. Cherkasov A. I. Etnokul'turnaya mozaika i mezhetnicheskie otnosheniya v Kanade. Russkie kanadtsy [Ethnocultural mosaic and interethnic relations in Canada. Russian Canadians]. Available at: http://www.niworld.ru/Statei/cherkasov/n1.htm (accessed 14 February 2016).

22. Calgary Russian Community. Available at: http://zarubegom.com/russkayaobshhina-kalgari/ (accessed 07 April 2016).

23. Sanadian Multiculturalism Act. Available at: http://www.laws.justice.gc.ca/e n/c-18.7/30207.html (accessed 04 March 2015).

24. Donskov A., ed. Sergej Tolstoys and the Doukhobors: A Journey to Canada (Diary and correspondence). Ottawa: University of Ottawa, 1998. 402 p.

25. Multicultural Sanada. Encyclopedia of Canada's Peoples. Available at: http://www.multiculturalcanada.ca/Encyclopedia/A-Z/i5/1 (accessed 05 September 2013).

26. Pierce R. A. Russian Canadians. Available at: http://www.thecanadianen cyclopedia.ca/en/article/russian-canadians/ (accessed 20 November 2016).

27. Russian-Canadian Cultural Aid Society. Available at: https://www.rcchf.ca/ (accessed 14 March 2016).

28. Statistics Canada. Data tables. 2016 Census. Ethnic Origin (279). Available at: http://www12.Statcan.gc/census-resensement/2016/dp-pd/dt-td/ (accessed 20 February 2020). 